\title{
What Drives Foreign Direct Investment into Emerging Markets? : Evidence from Turkey
}

\section{SULEYMAN TULUG OK}

To cite this article: SULEYMAN TULUG OK (2004) What Drives Foreign Direct Investment into Emerging Markets? : Evidence from Turkey, Emerging Markets Finance and Trade, 40:4, 101-114

To link to this article: http://dx.doi.org/10.1080/1540496X.2004.11052578

曲 Published online: 07 Dec 2014.

Submit your article to this journal ¿त

Џ Article views: 49

Q View related articles $₫$

Citing articles: 4 View citing articles एत 
Emerging Markets Finance and Trade, vol. 40, no. 4, July-August 2004, pp. 101-114.

(C) 2004 M.E. Sharpe, Inc. All rights reserved.

ISSN 1540-496X/2004\$9.50+0.00.

\title{
SULEYMAN TULUG OK
}

\section{What Drives Foreign Direct Investment into Emerging Markets?}

\author{
Evidence from Turkey
}

\begin{abstract}
The total volume of foreign direct investment (FDI) has increased immensely over the past decade and has become an important impetus behind the economic growth in developing countries. This paper examines the driving factors of FDI in Turkey. The data were collected through a survey of managers and expatriates of firms with foreign capital operating in Turkey and analyzed using nonparametric and parametrical statistical tests. The results show that foreign investors in Turkey regard economic and political instability as the most important barrier and an overwhelming majority of the respondents recommend the establishment of political stability in the country.
\end{abstract}

Key words: foreign capital, FDI, foreign direct investment, foreign investment, FDI in emerging markets, FDI in Turkey.

Countries seek for means such as foreign capital to best utilize resources to increase their economic strength and prosperity. Among many forms of foreign capital, the most beneficial and sought after is foreign direct investment (FDI). The UNCTAD World Investment Report (2002) shows that the total FDI inflows around the world amounted to $\$ 735$ billion in the year 2001.

Turkey has a fifty-year history of commitment to foreign investment, yet the policy itself only materialized during the 1980s, starting on January 24 , 1980, with the implementation of a comprehensive economic stabilization and liberalization program. However, between 1980 and 2001, Turkey's performance in the field has been below expectations and has not reached the potential to which the country is trusted. The average annual level of authorized FDI has been around $\$ 1.4$ billion,

Suleyman Tulug Ok (tulug@bilkent.edu.tr) is an instructor at Bilkent University, Department of Management, Ankara, Turkey. 
and the actual inflow was around $\$ 690$ million per year during this period. It is only after 1990 that Turkey has been able to achieve a level of $\$ 1$ billion in actual FDI flow per year, while during the same period there was an almost fivefold increase in the total volume of foreign investment in the world (Foreign Direct Investment Report 2001-2002).

The aim of this research is to determine the reasons Turkey does not rank among the top countries that attract the most FDI, despite all of its distinctive competencies and competitive advantages. We also analyze the problems that present barriers for FDI entry into Turkey and present recommendations to attract more foreign investment.

\section{Research Methodology}

Oktay (1996), Tuncer (1996), and Onaner (1998) studied and offered reasons foreign investors abstained from the Turkish market. The following variables were identified as the main barriers to FDI entry into Turkey:

1. high inflation,

2. economic and political instability,

3. defaults by governments and state authorities on promises made to foreign investors,

4. high credit costs,

5. frequent changes in rules and legislation,

6. lack of protection of intellectual property rights and competition,

7. lack of implementation of inflation accounting,

8. excessive bureaucracy,

9. high uncertainty,

10. acts of terrorism,

11. failure to respect and comply with international agreements,

12. informal economy, and

13. excessive government interference and involvement in the economy.

We carried out a field survey on these issues related to FDI in Turkey and tested four hypotheses:

H1: The predetermined set of thirteen problems listed above can be divided up into more clear and distinct subgroups that exhibit similar characteristics and show parallel behavior.

H2: A clear difference exists between the ranks in terms of importance attached to the problems by the respondents.

H3: There is a parallelism (association) between the ranking tendencies of the respondents, that is, respondents generally make ranking choices in the same direction.

H4: There are correlations between the rating and ranking tendencies of the respondents and the different demographic criteria; namely, capital level of the 
firm, economic sector, foreign participation share, country of origin, and number of employees.

Data were obtained by conducting a mail survey through a questionnaire that was developed and administered to a predetermined sample of respondents. The target population of the research was all firms with foreign capital operating in Turkey - a total of 3,707 firms. The sample chosen for research was top executives/ expatriates of 175 firms, all of which are YASED (Foreign Investors Association) members. The duration of the survey was eight weeks. Out of the 175 people who were contacted and requested to participate in the survey, 35 had faulty/changed addresses or changed respondents, reducing the number of eligible participants to 140. There were 66 questionnaires completed and returned, resulting in a response rate of 47 percent. Participation was voluntary and the respondents were assured of the anonymity and confidentiality. The questionnaire had ten questions divided into four instruments: level of importance scale, importance ranking scale, an openended question on "recommended solutions," and seven demographic questions.

\section{Level of Importance Scale}

The interval scale comprised thirteen different criteria on a seven-point Likert scale utilizing the bipolar adjectives "not a problem" and "very important problem"; the score " 1 " stood for "not a problem" and "7" stood for "very important problem" and respondents were asked to rate the thirteen different predetermined problems faced by foreign investors in Turkey according to their level of importance on the seven-point scale. An open-end "other" option was also provided with this question to gather information on additional problems perceived by the foreign investors and their importance ratings.

Importance Ranking Scale

The same thirteen criteria were used in the ordinal scale. This time the respondents were asked to rank the problems from 1 to 13 , with rank 1 assigned to the most important problem and rank 13 assigned to the least important. Each rank was to be assigned to only one problem. Here again, in addition to the thirteen criteria, an "other" open-end option was included in order to collect additional views and opinions on the subject.

Finally, an open-ended question was posed for recommended solutions pertaining to the indicated problems. Three nominal scales for capital level, sector of activity, country of origin, as well as two ratio scales for foreign participation share and total number of employees were included to gather demographic information on the respondents.

\section{Data Analysis and Hypothesis Testing}

Data analysis and hypothesis testing were carried out through nonparametric and parametrical statistical tests. Since the main objective of the research is to measure 
the importance of the problems, first the reliability and factor analysis of the level of importance scale were carried out.

\section{Level of Importance Scale}

First, the Cronbach's alpha reliability test of the level of importance scale was conducted. Cronbach's alpha measures how well a set of items (or variables) measures a single unidimensional latent construct (Hatcher 1994). It is a coefficient of reliability (or consistency). As Cronbach's alpha increases, so does reliability. Nunnaly (1978) has indicated 0.7 to be an acceptable reliability coefficient, but lower thresholds are sometimes used in the literature. In our case, $\alpha$ came out as 0.7747 , indicating that the scale was reliable. Hence, it was confirmed that we could use all thirteen criteria to find a total score. To test $\mathrm{H} 1$, we performed a factor analysis using the principle component method and varimax rotation (Maxim 1999; McPherson 2001). The result was four factors: economic, confidence, international compatibility, and red tape. Since a factor should have at least two items, the high credit cost item was not a factor but a stand-alone criterion.

To test the "rating" part of H4 using the level of importance scale, we first investigated whether the degree of importance given to the existing problems (i.e., seriousness of the problems as perceived by the foreign investors) differs with the capital level of their respective firms. For this purpose, a one-way analysis of variance (ANOVA) test was performed. We found no significant difference between the total scores of different capital levels $(F=0.2273, p=0.877)$. Similarly, we also carried out ANOVA tests for the four factors and the capital level and found no significant differences between the different capital levels in any of the factors. Second, to see if the degree of seriousness of the problems as perceived by the foreign investors shows differences from one country of origin to the other, we implemented a one-way ANOVA test. The results yielded $F=0.5247$ with $p=$ 0.8647 , indicating no significant differences between the scores of the four factors in relation to the different countries of origin either. Third, to investigate if the degree of importance assigned to the problems varies among different economic sectors, we performed a $t$-test and found no significant difference between the total scores of the manufacturing and services sectors $(t=-0.87, p=0.387)$. Finally, to examine the correlation between the degree of seriousness of the problems and the two variables foreign participation share and number of employees working at the company, the Pearson correlation coefficient was used. There was no significant correlation between the total score (degree of seriousness assigned to the problems) and the two variables employment and participation; but we found a small, negative correlation between foreign participation share and total number of employees $(r=-0.3864, p=0.002)$.

Other problems that were specified by the respondents and added to the level of importance scale, along with their frequency (number of respondents reporting) and importance rating, were reported in Table 1. Responses to the open-end "other" 
Table 1

Responses to the "Other" Option Provided in the Level of Importance Scale

\begin{tabular}{|c|c|c|}
\hline & Frequency & $\begin{array}{l}\text { Importance } \\
\text { rating }\end{array}$ \\
\hline Corruption & 3 & 7 \\
\hline Concessions and international arbitration & 2 & 7 \\
\hline $\begin{array}{l}\text { Uneven distribution of income and wealth that lin } \\
\text { market growth because of lack of affordability }\end{array}$ & 1 & 7 \\
\hline $\begin{array}{l}\text { Application of laws and justice } \\
\text { (court cases unsure) }\end{array}$ & 1 & 6 \\
\hline $\begin{array}{l}\text { Continuous revaluation of the Turkish lira } \\
\text { versus the euro }\end{array}$ & 1 & 6 \\
\hline $\begin{array}{l}\text { Different government offices giving contradictory } \\
\text { decisions or recommendations }\end{array}$ & 1 & 6 \\
\hline Education and training & 1 & 6 \\
\hline Enforcement of law & 1 & 6 \\
\hline Legal system dysfunctional & 1 & 6 \\
\hline High taxes (value-added tax, special taxes) & 1 & 6 \\
\hline Unqualified people in bureaucracy & 1 & 5 \\
\hline
\end{tabular}

option were not included in the statistical analysis since they were used to gather additional information on the subject.

Importance Ranking Scale

To test H2, we first conducted a Friedman two-way ANOVA test. At a 99 percent confidence interval, we found a significant difference and the mean ranks as given in Table 2. The lower the mean rank, the higher the level of importance assigned to the problem by the respondents.

In addition, to match each problem against the other twelve and to see the ranking differences between all such pairs, we applied seventy-eight Wilcoxon matchedpairs signed-ranks tests and obtained the results shown in Table 3. To test H3, the estimated Kendall coefficient of concordance indicated significant, but a low association $(W=0.2610, p=0.0000)$. To test the "ranking" part of H4 using the importance ranking scale, we first investigated whether the ranks assigned to the problems differ with different levels of capital. For this purpose, nonparametric KruskalWallis one-way ANOVA tests were conducted separately for all the thirteen problems against the variable capital level. We found a significant difference between the ranks given to the problem "high uncertainty" for different levels of firm capi$\operatorname{tal}\left(\chi^{2}=9.8956, p=0.0195\right)$. 
Table 2

Friedman Two-Way ANOVA Test of the Importance Ranking Scale

\begin{tabular}{lc} 
Variable & Mean rank \\
\hline High inflation & 4.40 \\
Economical and political instability & 2.69 \\
Defaults by governments and state authorities on promises made & 6.55 \\
$\quad$ toward foreign investors & 6.46 \\
High credit costs & 6.46 \\
Frequent changes in rules and legislation & 7.12 \\
Lack of protection of intellectual property rights and competition & 7.65 \\
Lack of implementation of inflation accounting & 7.12 \\
Excessive bureaucracy & 5.93 \\
High uncertainty & 9.49 \\
Acts of terrorism & 9.24 \\
Failure to respect and comply with international agreements & 9.62 \\
Informal economy & 8.28 \\
Excessive government interference and involvement in the economy & \\
$N=65$ & \\
chi-square = 203.1109 & \\
degree of freedom = 12 & \\
significance = 0.0000 & \\
Most important: rank $1 ;$ least important: rank 13. & \\
\hline
\end{tabular}

For all other problems, no significant difference was found. Second, to examine whether the ranks assigned to the problems differ according to economic sectors, a Mann-Whitney $U$-test was performed for all problems against the variable sector. We found a significant difference between the ranks given to the problem "high credit costs" by the representatives of the manufacturing and services sectors $(U=348, p=0.0274)$. The manufacturing sector, with a lower mean rank, rated the problem higher than the services sector as it is viewed more important. Similarly, we found a significant difference between the ranks given to the problem "informal economy" by the representatives of the manufacturing and services sectors ( $U=324, p=0.0103$ ). Again, the manufacturing sector, with a lower mean rank, rated the problem higher than the services sector. For all other problems, no significant difference was found between the two sectors. Third, to determine whether a relation existed between the ranks assigned to each of the thirteen problems and the two variables employment and participation, twenty-six Spearman correlation coefficient tests were carried out. We found a low, positive correlation between the ranks assigned to the problem "frequent changes in rules and legislation" and employment $\left(r_{s}=0.2487, p=0.049\right)$. Similarly, a low, positive correlation was found between the ranks assigned to the problem "excessive bureaucracy" 


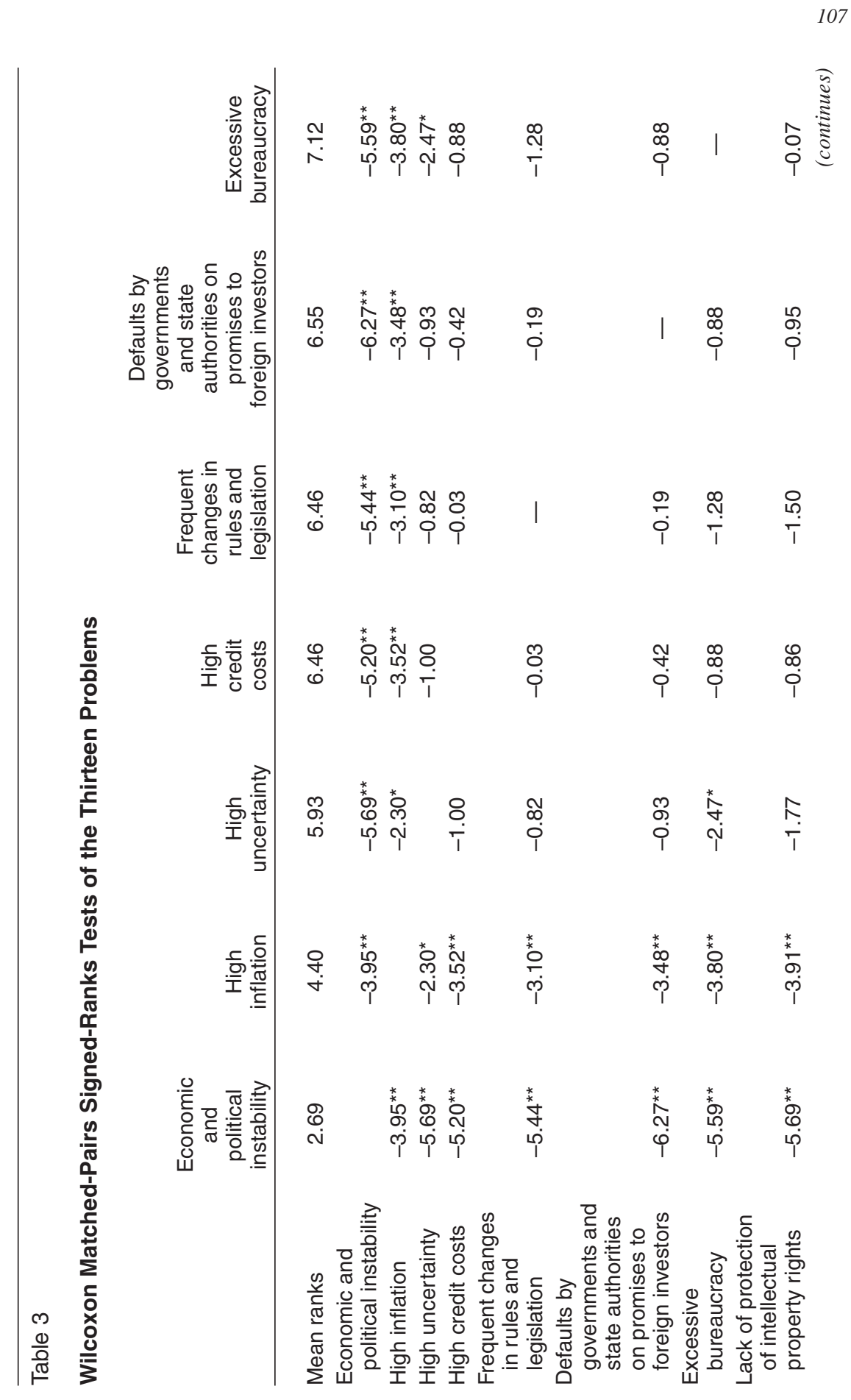




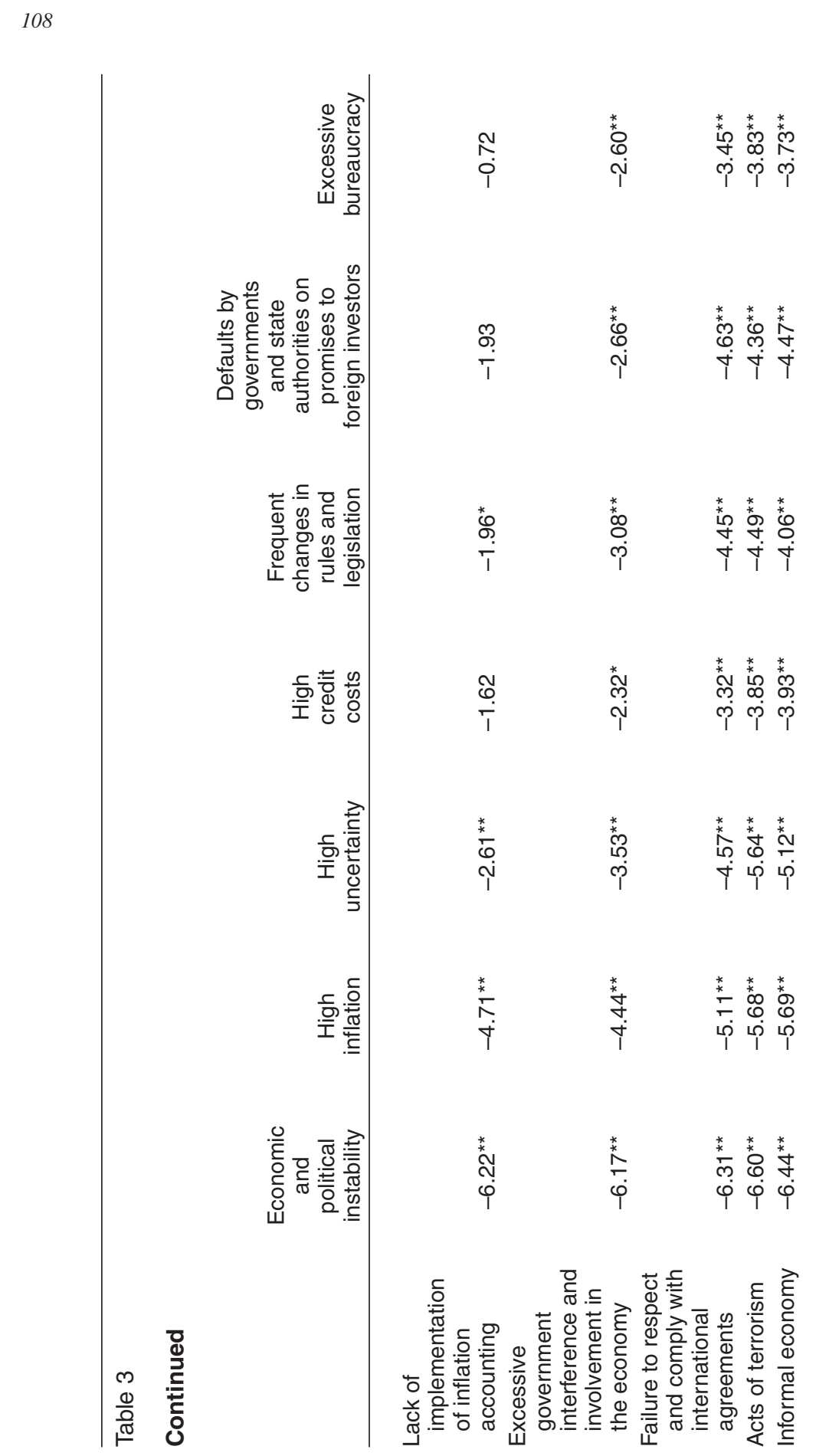




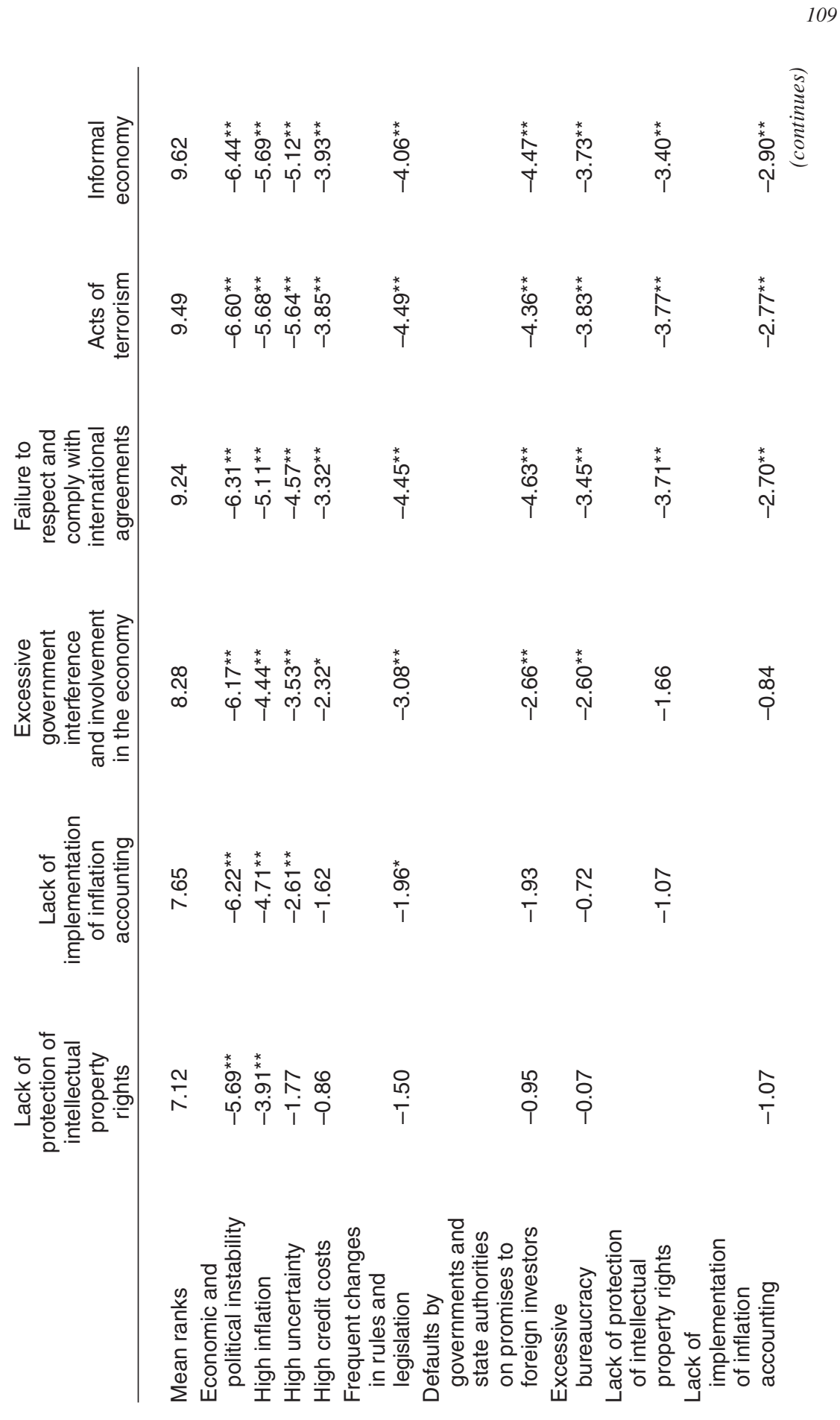




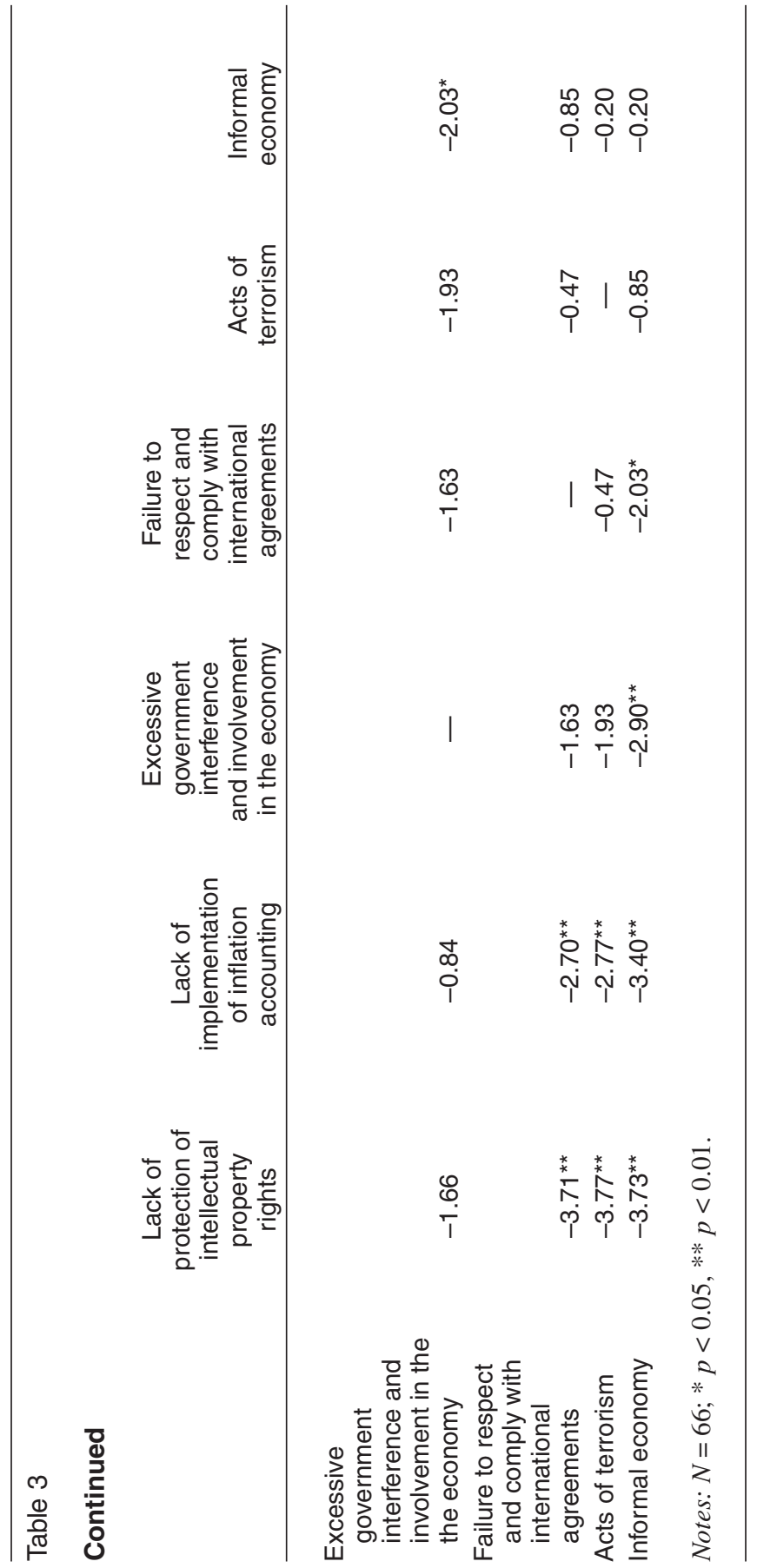


and employment $\left(r_{s}=0.2501, p=0.048\right)$. For all other problems, there was no significant correlation with the two variables employment and participation.

Other problems that were specified by the respondents and added to the Importance Ranking Scale included the need for better and more effective enforcement of law, highness of the taxes (especially value-added tax and other special taxes), malfunction of the legal system and the need for continuous adjustment of the Turkish lira against the euro in line with inflation. Responses to the open-end "Other" option was not included in the statistical analysis since these were used merely to gather additional information on the subject.

Open-Ended "Recommended Solutions" Question

Among the sixty-six respondents to the survey, forty-three answered the openended "recommended solutions" question. The results and the distribution of answers are shown in Table 4.

\section{Discussion of Results and Conclusion}

The findings suggest that the thirteen problems identified by previous studies can be clustered into four different subgroups with similar characteristics:

- economic factors: lack of implementation of inflation accounting, informal economy, and high inflation;

- confidence factors: high uncertainty, acts of terrorism, and economic and political instability;

- international compatibility factors: defaults by governments and state authorities on promises made toward foreign investors, failure to respect and comply with international agreements, and lack of protection of intellectual property rights and competition;

- red-tape factors: excessive bureaucracy, excessive government interference and involvement in the economy, and frequent changes in rules and legislation.

A fifth, stand-alone criterion was high credit costs, which was evidently assessed as an entirely separate issue by the respondents.

While investigating the relationship between the level of importance assigned to the problems and the different company criteria, we observed a low and negative correlation between foreign participation share and total number of employees. This finding suggests that as the foreign participation share in the company increases, we observe a parallel decrease in the number of people employed in the company. This could possibly be attributed to the well-known observation that foreigners put more emphasis on efficiency and cost saving and abstain from hiring and employing unnecessary personnel.

No other interrelationship was found between the degree of importance given to the problems and the different company criteria. The most important other problems specified and highly rated by the foreign investors were corruption, conces- 
Table 4

Open-Ended Responses to the Question "What Would Be Your Recommendation(s) for the Solution of These Problems?" (based on 43 participants responding to the question)

Number of participants reporting

Political stability and strong governments for long-term decisions and structural reforms in order to improve and stabilize the economic environment

Change of the election system and political parties' law to increase political stability

Cut budget deficit and internal debt; bring down inflation

Privatization

Apply international laws and regulations to attract foreign investors: international arbitration, protection of intellectual property rights, and inflation accounting

Small size state-less government/state intervention and regulation

Allocate more money into education/training, leading to more qualified personnel and better (higher income) jobs

Turkey has to improve its public relations and promotional activities and market itself better to the rest of the world

Better bureaucracy

Improve the legal system-justice reform

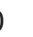

A better foreign investment administration and special attention given to this issue by the government

A more open, incentive, democratic system

Better organized sector representation

Establish transparent status governing foreign investment

Formation of an economic board/committee of economists with the objective of making recommendations to the government

Have better politicians

Integration with the European Union (ultimately)

Liberalization

Long-term institution of values back into Turkish culture

Make new and applicable regulations on banking system and fiscal law

More effective taxation system to reduce inflation

Only time and flow of events will determine the outcome

Social responsibility awareness_-make people hold politicians accountable

Social security reform

Unfair competition (nonrecorded economy) has to be controlled

Unfair income distribution has to be adjusted

YASED (Foreign Investors Association) 
sions and international arbitration, and uneven distribution of income and wealth in Turkey.

Next, we found clear differences between the ranks given to the problems by the respondents. The two highest ranked problems were economic and political instability and high inflation. The other three groups of problems showed no statistically significant ranking differences between themselves. The first group included high uncertainty, high credit costs, frequent changes in rules and legislation, defaults by governments and state authorities, and excessive bureaucracy, while the second group comprised of lack of protection of intellectual property rights and lack of implementation of inflation accounting. The final group constituted four problems: excessive government interference and involvement in the economy, failure to respect and comply with international agreements, acts of terrorism, and informal economy, completing the set of thirteen. The group of two including the "lack" problems actually displayed no significant detachment from its predecessor group of five (high uncertainty and so on) with higher rankings. However, we observed a clear difference between these two groups of problems in their behavior toward the problem of excessive government interference and involvement in the economy. There was a significant difference between the "excessive government" problem and all the problems in the group of five. Conversely, no significant difference was observed between this problem and the group of two (see Table 3).

The parallelism in the ranking tendencies of the respondents was established by using the concordance test. This result is expected since all foreign capital firms in Turkey face similar problems and hence their rankings are similar to each other. The finding that association seems to be low could be due to a large set of thirteen problems and we asked the respondents to rank them all. If we had given them merely the top five problems, the concordance probably would have been much higher. Besides, as we will see below, no significant differences of the rankings with any of the demographic (company) criteria was found, which supports and verifies the concordance result.

Even though the analysis did not indicate any significant interrelationship between the ranks assigned to the problems and the different company criteria, we found significant difference between the ranks given to the problem "high uncertainty" for different levels of firm capital. This could be attributed to the fact that as the capital level of the firm increases, so does the investment of the foreigners and the risk they are taking in a foreign country. Hence it is natural that as their investment increases, so does their uneasiness and sensitivity toward a high uncertainty atmosphere because of the higher uncertainty.

Next, we found significant difference between the ranks given to the problem "high credit cost" by the representatives of manufacturing and services. The manufacturing sector, with a lower mean rank, rated the problem higher than the services sector and viewed it more important. Again, this is to be expected since a manufacturing enterprise usually has more FDI than a service enterprise and operates with more external borrowing, especially in the form of bank credits and 
loans. Therefore, high credit costs are regarded as a more serious problem by the manufacturers and hence ranked higher.

Similarly, we found significant difference between the ranks given to the problem "informal economy" by the representatives of manufacturing and services. Again, the manufacturing sector, with a lower mean rank, rated the problem higher than the services sector and viewed it as more important. Here, the case could be made for the informal economy in Turkey, which has a more adverse effect on the manufacturing sector since the products traded within this unregistered business activity are mostly substitutes, hence direct competitors of products made by registered manufacturing firms.

A low and positive correlation exists between the ranks assigned to the problem "frequent changes in rules and legislation" and employment. It appears that as the total number of employees in a company increases and the organization gets bigger, so do the complexity of the internal procedures and the difficulty to adapt to change. Hence, whenever a new rule, regulation, or law comes out, it is more difficult for a larger company to make the transition and adapt to the change. Naturally, as the frequency of these changes increases, so does the magnitude of the problem for such organizations.

Very closely linked to the above observation, we also discovered a low and positive correlation between the ranks assigned to excessive bureaucracy and employment. Exactly the same reasoning and logic as above could be utilized for this case since the two factors, "excessive bureaucracy" and" frequent changes in rules and legislation," reflect similar problems.

Overall, the results indicate that foreign investors regard economic and political instability as the most serious FDI barrier and hence an overwhelming majority of the respondents recommend the establishment of political stability. As political stability improves and governments stay in power relatively long term, foreign investors are likely to invest more in Turkey.

\section{References}

Foreign Direct Investment Report 2001. 2002. Ankara: General Directorate of Foreign Investment.

Hatcher, L. 1994. A Step-by-Step Approach to Using the SAS(R) System for Factor Analysis and Structural Equation Modelling. Cary, NC: SAS Institute.

Maxim, P.S. 1999. Quantitative Research Methods in the Social Sciences. New York and Oxford: Oxford University Press.

McPherson, G. 2001. Applying and Interpreting Statistics, 2d ed. New York: Springer.

Nunnally, J.C. 1978. Psychometric Theory, 2d ed. New York: McGraw-Hill.

Oktay, M. 1996. Turkish Business Life via the Eyes of Foreign Businessmen. Istanbul: Istanbul Chamber of Industry, Customs Union Information Office.

Onaner, M. 1998. Investment in Turkey. Ankara: Undersecretariat of the Treasury.

Tuncer, E. 1996. "A General Look at Foreign Capital” [in Turkish]. Dunya NewspaperForeign Investors Supporting the Turkish Economy Special Supplement, May 23.

UNCTAD. 2002. UNCTAD World Investment Report 2002: Transnational Corporations and Export Competitiveness. New York: United Nations. 